\title{
Experimental Characterization of Intergranular Exchange Coupling in CoCrTaPt and CoNiCrPt Thin Film Media
}

\author{
T. SHIMATSU, D. D. DJAYAPRAWIRA, M. TAKAHASHI and T. WAKIYAMA
}

Dept. of Electronic Engng., Tohoku University, Sendai 980-77 Japan

Abstract- Quantitative characterizations of magnetic anisotropy of grains and intergranular coupling were carried out in $\left(\mathrm{Co}_{86} \mathrm{Cr}_{12} \mathrm{Ta}_{2}\right)_{100-X} \mathrm{Pt}_{X}(\mathrm{X}=1 \sim 9)$ and $\left(\mathrm{Co}_{62.5} \mathrm{Ni}_{30} \mathrm{Cr}_{75}\right)_{100-X} \mathrm{Pt}_{\mathrm{X}}(\mathrm{X}=0 \sim 16)$ thin film media, by magnetic torque and $\Delta \mathrm{M}$ analyses. In both materials, magnetocrystalline anisotropy field of grains $\mathrm{H}_{k}$ grain increases twice as large as those of $\mathrm{X}=0$ with increasing $X$ to about $9 a t \%$, which plays a main role in increasing $\mathrm{H}_{c}$. However, $\mathrm{H}_{\mathrm{c}} / \mathrm{H}_{\mathrm{k}}$ grain decreases with increasing $X$ in both media. In CoCrTaPt media, the decrement of $\mathrm{H}_{\mathrm{c}} / \mathrm{H}_{\mathrm{k}}{ }^{\text {rrain }}$ is found to be mainly caused by the increment of intergranular exchange coupling. In $\mathrm{CoNiCrPt}$ media, it is suggested that the change of $\mathrm{c}$-axes directions from in plane to normal mainly causes the decrement in $\mathrm{H}_{\mathrm{c}} / \mathrm{H}_{\mathrm{k}}$ grain. Furthermore, to examine the effect of intergranular coupling on magnetic properties by means of $\Delta \mathrm{M}$ plot, it is clarified that the difference of $\mathrm{H}_{\mathrm{k}}$ grain should be taken into account.

\section{INTRODUCTION}

Intergranular coupling of magnetization degrades the appearance of high coercive force and also much influences media noise [1]. The knowledge for the degree of intergranular coupling of the media is indispensable to realize high density magnetic recording $[2,3]$. In this study, quantitative characterizations of magnetic anisotropy of grains and intergranular coupling were carried out by both magnetic torque and $\Delta \mathrm{M}$ plot analyses in $\left(\mathrm{Co}_{86} \mathrm{Cr}_{12} \mathrm{Ta}_{2}\right)_{100-X} \mathrm{Pt}_{\mathrm{X}}(\mathrm{X}=1 \sim 8)$ and $\left(\mathrm{Co}_{62.5} \mathrm{Ni}_{30} \mathrm{Cr}_{7.5}\right)_{100}$ ${ }_{x} \mathrm{Pt}_{x}(X=0 \sim 16)$ thin film media. Magnetic properties in these media were discussed in connection with the magnetic anisotropy of grains and the strength of intergranular coupling of magnetization. The comparison of characterized results concerning intergranular exchange coupling between by magnetic torque analysis and by $\Delta \mathrm{M}$ plot was also made out.

\section{EXPERIMENTAL PROCEDURE}

$\left(\mathrm{Co}_{86} \mathrm{Cr}_{12} \mathrm{Ta}_{2}\right)_{100-x} \mathrm{Pt}_{x}$ and $\left(\mathrm{Co}_{62.5} \mathrm{Ni}_{30} \mathrm{Cr}_{7.5}\right)_{100-x} \mathrm{Pt}_{x}$ media were deposited by d.c. magnetron sputtering on non-textured glass substrates with the $\mathrm{Cr}$ underlayer of $2000 \AA$. Thickness of the magnetic layer was fixed at $400 \AA$. Concentration of $\mathrm{Pt}$ was controlled by the number of $\mathrm{Pt}$ plates on the alloy target of $\mathrm{Co}_{86} \mathrm{Cr}_{12} \mathrm{Ta}_{2}$ or $\mathrm{Co}_{62.5} \mathrm{Ni}_{30} \mathrm{Cr}_{7.5}$. The samples were deposited at the substrate temperatures of 150, 200 and $250^{\circ} \mathrm{C}$. The other conditions for the film fabrication were fixed. The concentration of $\mathrm{Pt}$ was examined by E.P.M.A.

Magnetization and remanence curves were measured by V.S.M. Before measuring the isothermal remanence curve, all the samples were acdemagnetized by decreasing the magnitude of applied magnetic field. Rotational hysteresis loss was measured by a high sensitive torque magnetometer.
Preferred grain orientation was analyzed by X-ray diffraction technique with Co-K $\alpha$ radiation.

\section{RESULTS AND DISCUSSION}

A. Coercive Force and Magnetic Anisotropy of Grains In all media, magnetic anisotropy was not observed in hysteresis loops in the film plane. In Fig.1, coercive force $\mathrm{H}_{c}$ in both kinds of media are plotted against $\mathrm{Pt}$ content. In CoCrTaPt media deposited at 150 and $200^{\circ} \mathrm{C}, \mathrm{H}_{\mathrm{c}}$ increases monotonically from about 1 to about $1.7 \mathrm{kOe}$ with increasing Pt from 0 to about 9 at $\%$. However, remarkable increase in $\mathrm{H}_{c}$ is not observed in the media deposited at $250^{\circ} \mathrm{C}$. Here, saturation magnetization $M_{s}$ shows a constant value of about $620 \mathrm{emu} / \mathrm{cc}$ independent of Pt content.

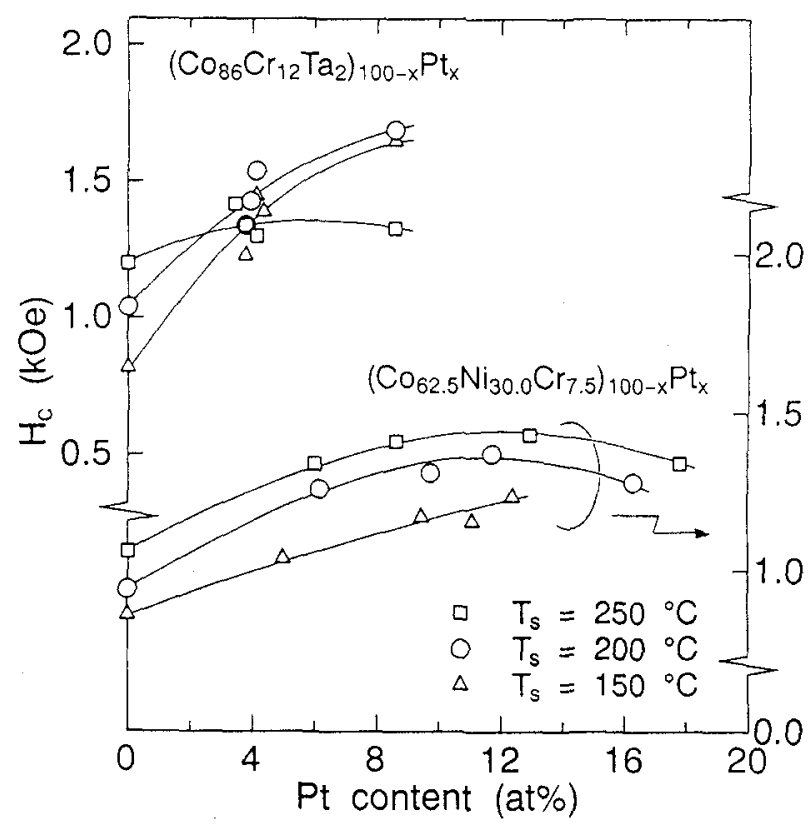

Fig.1 Change in $\mathrm{H}_{c}$ against $\mathrm{Pt}$ content in CoCrTaPt and CoNiCrPt media. 


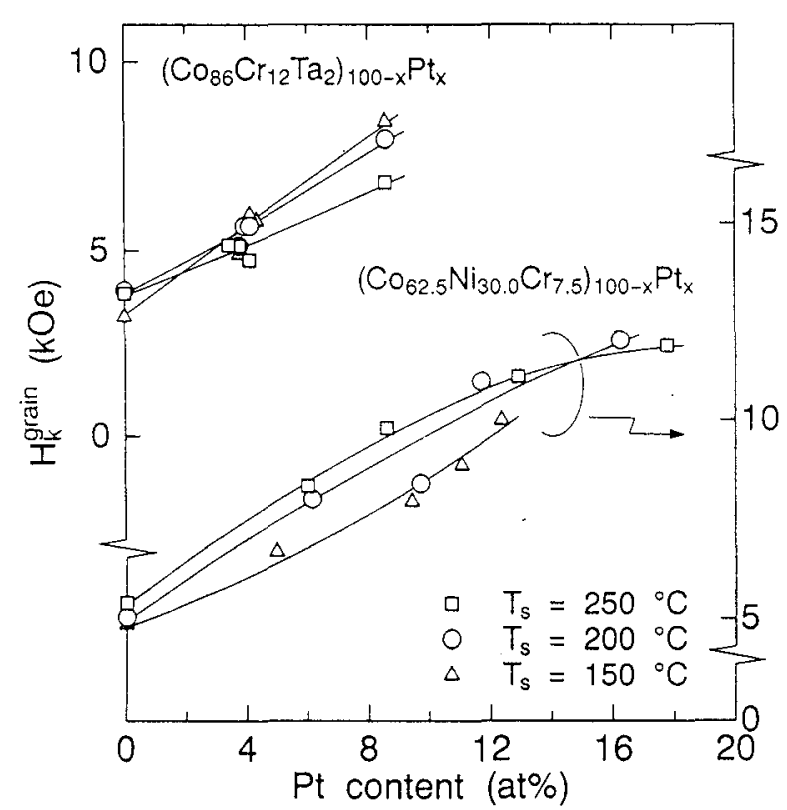

Fig.2 Change in $\mathrm{H}_{\mathrm{k}}^{\text {grain }}$ against $\mathrm{Pt}$ content in CoCrTaPt and CoNiCrPt media.

In CoNiCrPt media, $\mathrm{H}_{\mathrm{c}}$ monotonically increases with increasing $\mathrm{Pt}$ to about 12at\%. However, remarkable change in $\mathrm{H}_{c}$ is not found in the region beyond about 12 at $\% \mathrm{Pt}$. Here, $\mathrm{M}_{\mathrm{s}}$ in $\mathrm{CoNiCrPt}$ media decreases monotonically from about 850 to about 720 emu/cc as Pt increases from 0 to about 16 at $\%$.

On the other hand, the increase of intrinsic magnetocrystalline anisotropy of grains, due to the increase of soluted Pt into grains, is easily expected in both kinds of media. The increase of $\mathrm{H}_{c}$ with increasing $\mathrm{Pt}$ is assumed to be strongly correlated to the increment of the magnetocrystalline anisotropy of grains.

In Fig.2, the values of $\mathrm{H}_{\mathrm{k}}{ }^{\text {grain }}$ are shown against $\mathrm{Pt}$ content in the both kinds of media. Here, $\mathrm{H}_{\mathrm{k}}$ grain shows the value of magnetic anisotropy field of grains. This field was determined as the magnetic field where rotational hysteresis loss $W_{r}$ vanishes by an extrapolation method [2-4].

In the media without $\mathrm{Pt}, \mathrm{H}_{\mathrm{k}}$ grain shows about $4 \mathrm{kOe}$ in CoCrTa media and about $5 \mathrm{kOe}$ in CoNiCr media. In both kinds of media, $\mathrm{H}_{\mathrm{k}}$ grain gradually increases with increasing $\mathrm{Pt}$ and becomes twice as large as those without Pt at about 9at\% Pt. This increment of $\mathrm{H}_{\mathrm{k}}$ grain in both kinds of media means the increment of magnetocrystalline anisotropy of grains. Therefore, it is obviously concluded that the increment of $\mathrm{H}_{\mathrm{k}}$ grain due to the addition of $\mathrm{Pt}$ plays a main role in increasing $\mathrm{H}_{\mathrm{c}}$ in both kinds of media.

\section{B. Intergranular Coupling of Magnetization}

In Fig.3, the values of $\mathrm{H}_{c}$ normalized by $\mathrm{H}_{k}{ }^{\text {grain }}$ are plotted against Pt content in the both kinds of media.

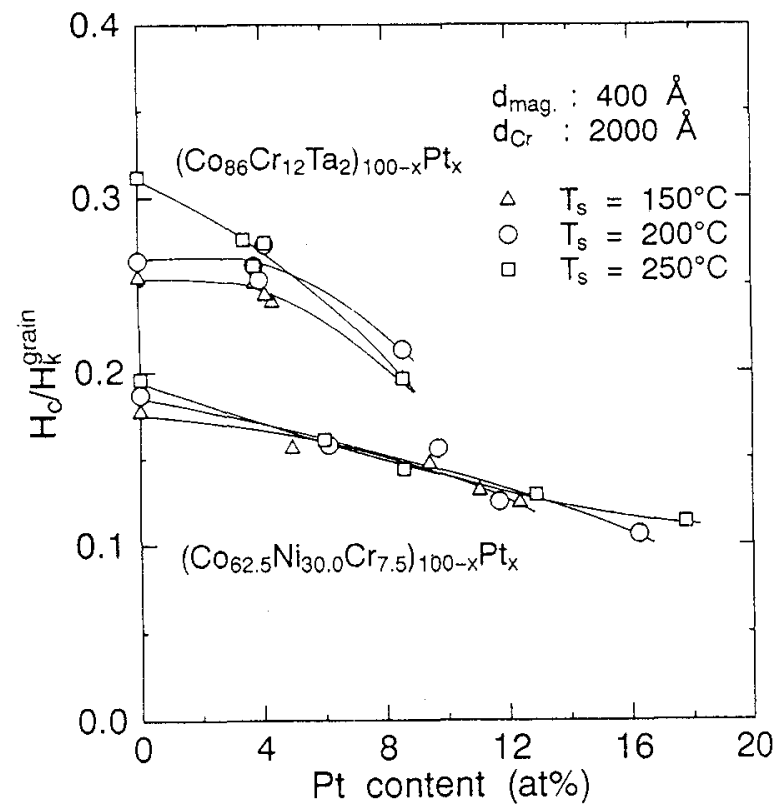

Fig.3 Change in $\mathrm{H}_{c} / \mathrm{H}_{\mathrm{k}}^{\text {grain }}$ against Pt content in CoCrTaPt and $\mathrm{CoNiCrPt}$ media.

In CoCrTaPt media deposited at 150 and $200^{\circ} \mathrm{C}$, $\mathrm{H}_{\mathrm{c}} / \mathrm{H}_{\mathrm{k}}{ }^{\text {grain }}$ keep the values at around 0.26 in the $\mathrm{Pt}$ content region up to about 6 at $\% \mathrm{Pt}$. With further increasing $\mathrm{Pt}$ to about 9at $\%, \mathrm{H}_{\mathrm{c}} / \mathrm{H}_{\mathrm{k}}{ }^{\text {grain }}$ gradually decreases to about 0.2 . However, in the media deposited at $250^{\circ} \mathrm{C}, \mathrm{H}_{\mathrm{c}} / \mathrm{H}_{\mathrm{k}}$ grain monotonically decreases from about 0.31 to about 0.2 as Pt content increases from 0 to about 9 at $\%$.

On the other hand, in CoNiCrPt media, the values of $\mathrm{H}_{c} / \mathrm{H}_{k}{ }^{\text {grain }}$ are smaller than those in CoCrTaPt media at the whole $\mathrm{Pt}$ content region. With increasing $\mathrm{Pt}$ content from 0 to about 12 at $\%, \mathrm{H}_{c} / \mathrm{H}_{\mathrm{k}}^{\text {grain }}$ monotonically decreases from about 0.19 to about 0.13 at all substrate temperatures examined.

In order to analyze this dependence of $\mathrm{H}_{\mathrm{c}} / \mathrm{H}_{\mathrm{k}}$ grain on Pt content in the both kinds of media, two possible origins will be discussed. One is grain orientation effect, the other intergranular (magnetostatic or exchange) coupling of magnetization.

Fig. 4 shows the $X$-ray diffraction patterns in CoNiCrPt media with different Pt content. With increasing Pt content, hcp-(100) and hcp-(002) peaks shift to lower $2 \theta$ values, which indicates the increments in lattice spacings of hcp-CoNiCrPt. For example, the hcp-(100) lattice spacing gradually increases to about $2 \%$ larger value by the addition of about 16 at $\% \mathrm{Pt}$ content. This increases in the lattice spacings of the hcp-CoNiCrPt indicate a monotonic increase of soluted $\mathrm{Pt}$ content into the $\mathrm{CoNiCr}$ grains. On the other hand, the ratio of the diffracted intensity from hcp-(100) plane to that from hcp-(002) plane $\mathrm{I}_{(100)} / \mathrm{I}_{(002)}$ gradually decreases with increasing $\mathrm{Pt}$ content, which indicates the change of the c-axes directions of $\mathrm{CoNiCrPt}$ grains 


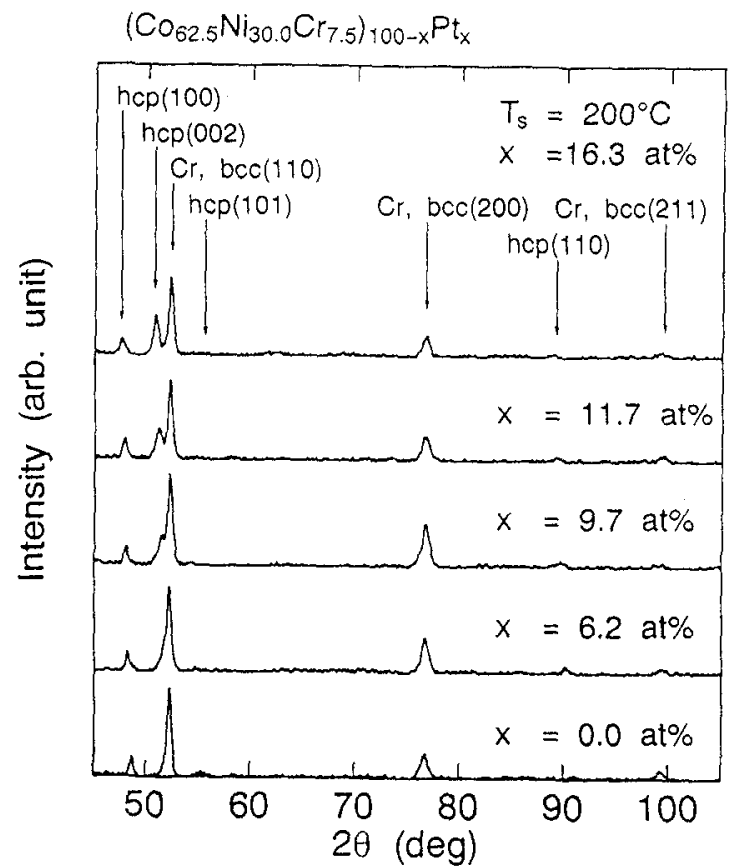

Fig.4 Dependence of $X$-ray diffraction patterns on Pt content in CoNiCrPt films.

from in plane to normal as Pt content increases. Here, $I_{(100)} / I_{(002)}$ was not dependent on the substrate temperature.

In CoCrTaPt media, the increase of lattice spacings of hcp-CoCrTaPt with increasing Pt content has been also observed in the similar way [4]. However, $\mathrm{I}_{(100)} / \mathrm{I}_{(002)}$ was independent of both the Pt content and the substrate temperature, and showed an almost constant value of about 0.8 [4]. This result means that remarkable difference of preferred grain orientation among those CoCrTaPt films does not exist and the c-axes directions of grains almost lie in the film plane.

On the other hand, in the case that the $\mathrm{H}_{c}$ value is mainly determined by the degree of magnetostatic coupling, $\mathrm{H}_{\mathrm{c}} / \mathrm{H}_{\mathrm{k}}$ grain should increase with decreasing $4 \pi \mathrm{M}_{\mathrm{s}} / \mathrm{H}_{\mathrm{k}}$ grain . Here, the ratio of $4 \pi \mathrm{M}_{\mathrm{s}}$ to $\mathrm{H}_{\mathrm{k}}^{\text {grain }}$ indicates the intrinsic strength of magnetostatic coupling effect on the decreasing of coercive force [3-5].

In Fig.5, the values of $4 \pi \mathrm{M}_{s} / \mathrm{H}_{\mathrm{k}}$ grain are plotted against Pt content in the both kinds of media. In the both kinds of media, $4 \pi \mathrm{M}_{\mathrm{s}} / \mathrm{H}_{\mathrm{k}}{ }^{\text {grain }}$ gradually decreases with increasing Pt content, however, $\mathrm{H}_{\mathrm{c}} / \mathrm{H}_{\mathrm{k}}{ }^{\text {grain }}$ also decreases as shown in Fig.3. Therefore, in the both kinds of media, the decrement of $\mathrm{H}_{\mathrm{c}} / \mathrm{H}_{\mathrm{k}}{ }^{\text {grain }}$ with increasing $\mathrm{Pt}$ content can not be simply explained by the change of the strength of intergranular magnetostatic coupling of magnetization.

In CoCrTaPt media presently examined, remarkable difference of preferred grain orientation is not found as has been mentioned above. Furthermore, the

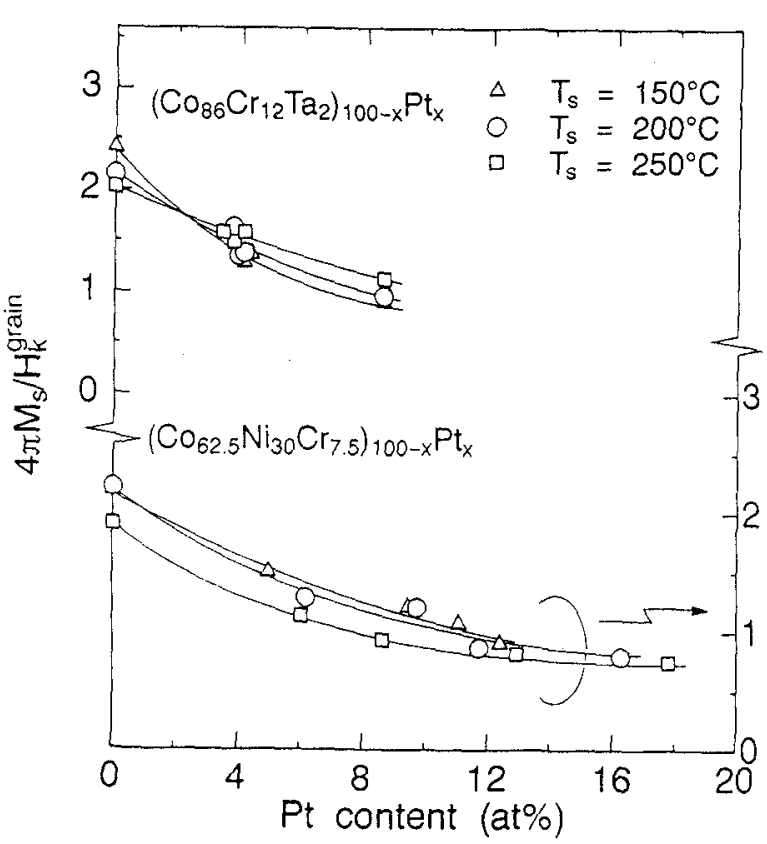

Fig.5 Change in $4 \pi \mathrm{M}_{\mathrm{s}} \mathrm{H}_{\mathrm{k}}$ grain against Pt content in CoCrTaPt and CoNiCrPt media.

decrement of $\mathrm{H}_{\mathrm{c}} / \mathrm{H}_{\mathrm{k}}$ grain with increasing Pt content can not be explained by the change of the strength of intergranular magnetostatic coupling of magnetization. Finally, the decrease of $\mathrm{H}_{\mathrm{c}} / \mathrm{H}_{\mathrm{k}}{ }^{\text {grain }}$ in CoCrTaPt media is concluded to be mainly caused by the increase of the strength of intergranular exchange coupling of magnetization.

On the other hand, in CoNiCrPt media, the c-axes directions of $\mathrm{CoNiCrPt}$ grains change from in plane to normal with increasing Pt content as shown in Fig.4. Decrement of in plane component of magnetocrystalline anisotropy decreases $\mathrm{H}_{c}$ in film plane. Therefore, it is not accurately known what is the main factor to decrease $\mathrm{H}_{\mathrm{c}} / \mathrm{H}_{\mathrm{k}}^{\text {grain }}$ with increasing $\mathrm{Pt}$, whether the decrement of in plane component of magnetocrystalline anisotropy or the increase of the strength of intergranular exchange coupling.

\section{Intergranular Coupling Characterized by $\triangle M$ Plot}

In order to develop the further examination concerning intergranular coupling, remanence curves measurement was carried out for all samples.

In Fig.6, the changes in $\triangle M$ against applied magnetic field were shown for both media. In each kind of medium, the results for the films with different amount of Pt content are shown.

In CoCrTaPt media, the maximum value $\Delta \mathrm{M}^{\max }$ gradually increases with increasing $\mathrm{Pt}$ content. It is considered $[6,7]$ that the strength of intergranular exchange coupling is the main factor to determine the magnitude of $\Delta \mathrm{M}^{\max }$. Therefore, the increment of 


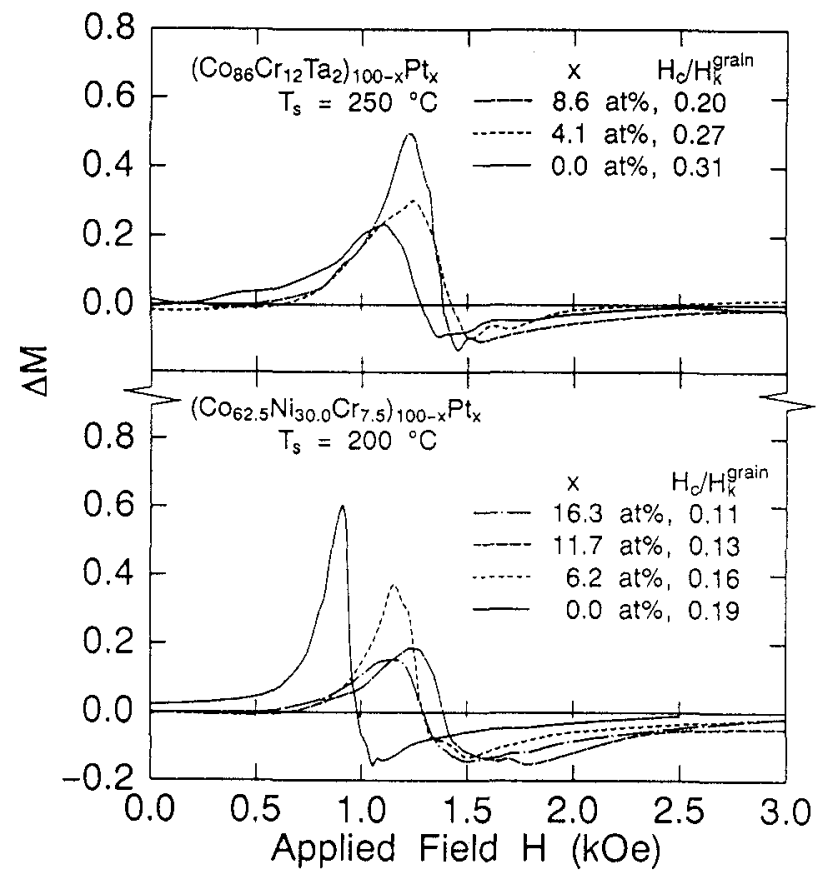

Fig.6 Dependence of $\Delta \mathrm{M}$ on Pt content in CoCrTaPt and CoNiCrPt media.

$\Delta \mathrm{M}^{\max }$ with increasing Pt suggests the increase of the strength of intergranular exchange coupling. On the contrary, in CoNiCrPt media, $\Delta \mathrm{M}^{\max }$ drastically decreases with increasing Pt content. In this material case, grain orientation also changes as a function of Pt content. Strictly speaking, the effect of grain orientation on the $\Delta \mathrm{M}^{\mathrm{max}}$ should be taken into account to discuss the correlation between the strength of intergranular coupling and $\Delta \mathrm{M}^{\max }$ exactly. However, the decrease of $\Delta \mathrm{M}^{\max }$ with increasing $\mathrm{Pt}$ indicates the possibility of the decrement of intergranular exchange coupling due to the increment of Pt content.

In Fig.7, the values of $\Delta \mathrm{M}^{\max }$ of all media are plotted against the values of $\mathrm{H}_{\mathrm{c}}$. Furthermore, in Fig. 8, $\Delta \mathrm{M}^{\max }$ are plotted against $\mathrm{H}_{\mathrm{c}} / \mathrm{H}_{\mathrm{k}}{ }^{\text {grain }}$.

As seen in Fig.7, no clear correlation between $\Delta \mathrm{M}^{\max }$ and $\mathrm{H}_{c}$ is observed. While by taking account of the values of $\mathrm{H}_{k}{ }^{\text {grain }}$, as shown in Fig.8, the clear dependence of $\Delta \mathrm{M}^{\text {max }}$ on $\mathrm{H}_{\mathrm{c}} / \mathrm{H}_{\mathrm{k}}$ grain is found in both kinds of media.

In CoCrTaPt media, $\Delta \mathrm{M}^{\text {max }}$ gradually increases with decreasing $\mathrm{H}_{c} / \mathrm{H}_{k}{ }^{\text {grain }}$. This result means that the decrease of $\mathrm{H}_{c} / \mathrm{H}_{k}$ grain is mainly caused by the increment of the strength of intergranular exchange coupling, which follows the result estimated by magnetic torque analysis mentioned above.

On the other hand, in the case that the change of grain orientation does not play a main role in determining $\mathrm{H}_{\mathrm{c}} / \mathrm{H}_{\mathrm{k}}$ grain value in CoNiCrPt media, the decrease of $\mathrm{H}_{\mathrm{c}} / \mathrm{H}_{\mathrm{k}}{ }^{\text {grain }}$ is mainly caused by the increment of the intergranular exchange coupling.

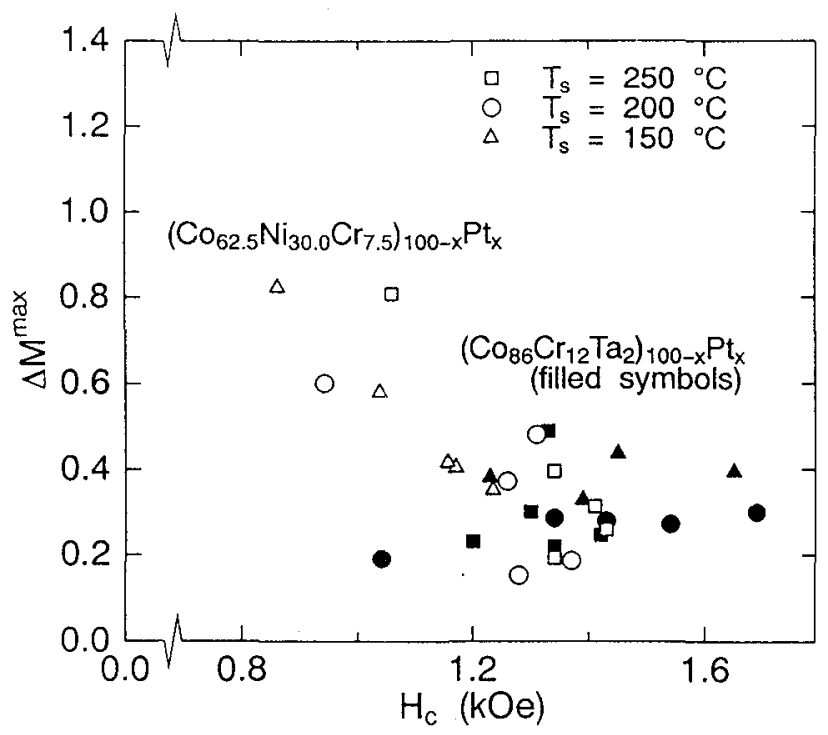

Fig.7 Correlation between $\mathrm{H}_{c}$ and $\Delta \mathrm{M}^{\max }$ in CoCrTaPt and CoNiCrPt media.

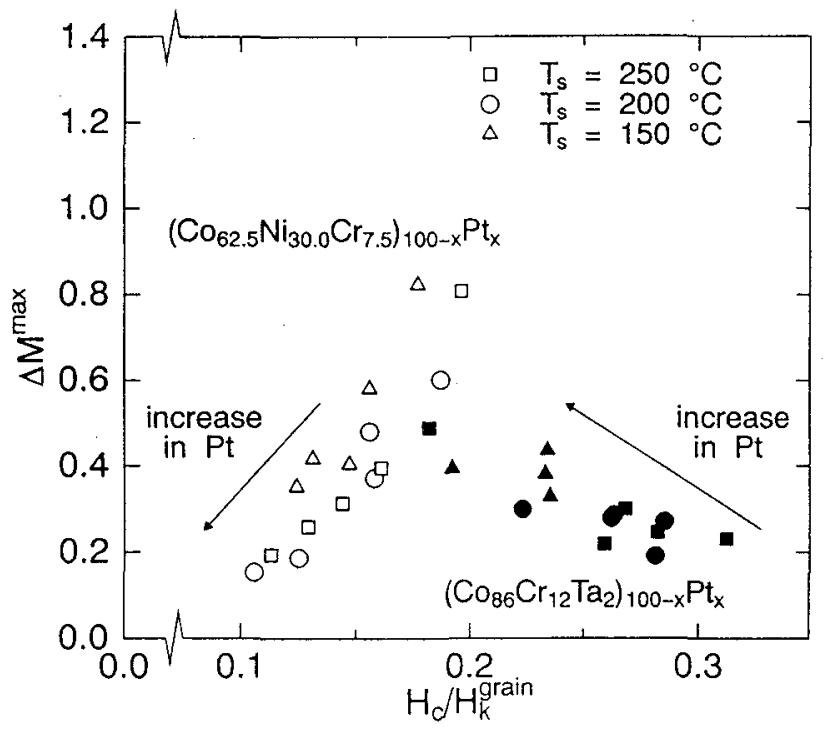

Fig.8 Correlation between $\mathrm{H}_{c} \mathrm{H}_{\mathbf{k}}$ grain and $\Delta \mathbf{M}^{\max }$ in CoCrTaPt and $\mathrm{CoNiCrPt}$ media.

Therefore, in this case, it is expected that $\Delta \mathrm{M}^{\max }$ gradually increases with decreasing $\mathrm{H}_{\mathrm{c}} / \mathrm{H}_{\mathrm{k}}{ }^{\text {grain }}$ like as in the CoCrTaPt case. However, on the contrary, $\Delta \mathrm{M}^{\text {max }}$ gradually decreases with decreasing $\mathrm{H}_{\mathrm{c}} / \mathrm{H}_{\mathrm{k}}$ grain in $\mathrm{CoNiCrPt}$ media. Finally, this result suggests that the decrease of $\mathrm{H}_{c} / \mathrm{H}_{k}$ grain in CoNiCrPt media presently examined is mainly caused by the change of c-axes directions from in plane to normal with increasing Pt content.

Furthermore, as has been mentioned above, no clear correlation between $\Delta \mathrm{M}^{\max }$ and $\mathrm{H}_{\mathrm{c}}$ is observed. This result means that the correlation between intergranular exchange coupling and magnetic properties can not be quantitatively discussed through only the $\Delta \mathrm{M}$ plot analysis. To examine the effect of 
intergranular coupling on magnetic properties by means of $\Delta \mathrm{M}$ plot, it is clarified that the difference of $\mathrm{H}_{\mathrm{k}}{ }^{\text {grain }}$ should be taken into account.

\section{SUMMARY}

1) In $\left(\mathrm{Co}_{86} \mathrm{Cr}_{12} \mathrm{Ta}_{2}\right)_{100-x} \mathrm{Pt}_{\mathrm{x}}$ and $\left(\mathrm{Co}_{62.5} \mathrm{Ni}_{30} \mathrm{Cr}_{7.5}\right)_{100-x} \mathrm{Pt}_{\mathrm{x}}$ media, magnetocrystalline anisotropy field of grains increases twice as large as those of $X=0$ with increasing $X$ to about 9at\%. This increment of $\mathrm{H}_{\mathrm{k}}{ }^{\text {grain }}$ plays a main role in increasing $\mathrm{H}_{c}$ in both kinds of media.

2) In $\mathrm{CoCrTaPt}$ media presently examined, the decrement of $\mathrm{H}_{c} / \mathrm{H}_{\mathrm{k}}{ }^{\text {grain }}$ with increasing Pt content is concluded to be mainly caused by the increment of the strength of intergranular exchange coupling of magnetization.

3) In $\mathrm{CoNiCrPt}$ media presently examined, it is suggested that the decrease of in plane component of magnetocrystalline anisotropy of grains, due to the change of the $\mathrm{c}$-axes directions from in plane to normal, plays a main role in decreasing $\mathrm{H}_{\mathrm{c}} / \mathrm{H}_{\mathrm{k}}{ }^{\text {grain }}$ with increasing $\mathrm{Pt}$.
4) In order to examine the effect of intergranular coupling on magnetic properties by means of $\Delta \mathrm{M}$ plot, it is clarified that the difference of $\mathrm{H}_{k}{ }^{\text {grain }}$ should be taken into account.

\section{REFERENCES}

[1] Tu Chen and T. Yamashita : IEEE Trans. Magn., Vol. MAG-24, 2700 (1988).

[2] M. Suekane, M. Miyamura, T. Shimatsu and M. Takahashi : J. Magn. Soc. Jpn., Vol.16, No.4, 655 (1992).

[3] T. Shimatsu, M. Takahashi, M. Suekane, M. Miyamura, K Yamaguchi and H. Yamasaki : The Proceedings of the 3rd IUMRS International Conference on Advanced Materials, Tokyo (1993).

[4] T. Shimatsu, S. Yokota, D. D. Djayaprawira, M. Takahashi and T. Wakiyama : J. Magn. Soc. Jpm., Vol. 18, No.2, 89 (1994).

[5] Jian-Gang Zhu and H. Neal Bertram: J. Appl. Phys., Vol.63, No.8, 3248 (1988).

[6] P. E. Kelly, K. O'Grady, P. I. Mayo and R. W. Chantrell :IEEE Trans Magn., Vol .MAG-25, 3881 (1989).

[7] P. I. Mayo, K. O'Grady, P. E. Kelly, J. Cambridge, I. L. Sanders, T. Yogi and R. W. Chantrell : J. Appl. Phys., Vol.69, 4733 (1991). 